\title{
Recent consumption of a large meal does not affect measurements of lung function
}

\author{
Elise CHU, ${ }^{1,2}$ Debbie BURTON, ${ }^{1,3}$ Nigel MCARDLE ${ }^{2,4}$ AND KeVIN GAIN ${ }^{2,4,5}$
}

\begin{abstract}
${ }^{1}$ School of Biomedical Sciences, Charles Sturt University, Wagga Wagga, New South Wales, ${ }^{2}$ Respiratory Medicine Department, Royal Perth Hospital, ${ }^{4}$ School of Medicine and Pharmacology, University of Western Australia, ${ }^{5}$ School of Physiotherapy, Curtin University of Technology, Perth, Western Australia and ${ }^{3}$ School of Medical and Applied Sciences, Central Queensland University, Rockhampton, Queensland, Australia
\end{abstract}

\begin{abstract}
Background and objective: It is currently recommended that patients avoid large meals prior to their lung function tests. The aim of this study is to determine whether this recommendation is necessary in clinical practice.

Methods: A randomized controlled cross-over trial was conducted. Subjects performed lung function tests (spirometry, measurement of lung volumes and gas transfer) prior to, directly following and $2 \mathrm{~h}$ after consuming a large breakfast. On the control arm, subjects performed the same lung function tests while fasting for the duration of the morning. The study subjects comprised 12 healthy subjects, 10 COPD patients and 10 patients with interstitial lung disease.

Results: There were no significant differences between measurements on the meal and control days for $\mathrm{FEV}_{1}, \mathrm{FVC}$, TLC or DL $\mathrm{DL}_{\mathrm{CO}}$. There were no significant changes with time in any of these parameters over the course of either the meal or control morning.

Conclusions: Common measures of lung function are not affected by the prior consumption of a large meal and it is unnecessary to advise patients to avoid a large meal prior to lung function assessment.
\end{abstract}

Key words: forced expiratory volume-time, lung function test, postprandial period, pulmonary diffusing capacity, total lung capacity.

\section{INTRODUCTION}

To obtain repeatability of lung function test results, all sources of technical and environmental variation must be controlled. This in turn will ensure the quality of information used for diagnosis and management of

Correspondence: Elise Chu, Respiratory Medicine Department, Royal Perth Hospital, GPO Box X2213, Wellington Street, Perth, WA 6847, Australia. Email: elise.chu@health.wa.gov.au

Received 27 October 2009; invited to revise 23 November 2009, 17 March 2010; revised 18 February 2010, 15 April 2010; accepted 17 April 2010 (Associate Editor: Chi Chiu Leung).

\section{SUMMARY AT A GLANCE}

The study aim was to determine the effect of a large meal consumed prior to lung function measurement. No effect of meal on $\mathrm{FEV}_{1}, \mathrm{FVC}$, TLC or $\mathrm{DL}_{\mathrm{CO}}$ was seen. This result does not support the recommendation that patients need to abstain from large meals prior to lung function testing.

respiratory disease. To this end, guidelines have been published to minimize intra-test variability and to decrease variability between testing centres. One recommendation by the American Thoracic Society (ATS) and European Respiratory Society (ERS) joint statement General considerations for lung function testing ${ }^{1}$ is that patients do not consume a large meal prior to testing. The American Association of Respiratory Care (AARC) considers consuming a large meal prior to testing, as a contraindication for measuring $\mathrm{DL}_{\mathrm{CO}}{ }^{2}$

A number of physiologic factors have the potential to impact a patient's respiration following a meal. In particular, cardiovascular, metabolic and gastrointestinal effects have been suggested to impact on lung function..$^{3-5}$ The primary reference ${ }^{6}$ given by previous ATS guidelines ${ }^{7}$ hypothesizes that following a meal, blood is redistributed from the pulmonary capillaries to the other organs, leading to a decrease in DL $\mathrm{Co}_{\mathrm{CO}}$. In the current ATS/ERS guidelines ${ }^{1}$ no reference to the rationale for avoiding a large meal prior to testing is provided.

Adherence to pre-test recommendations, for example, refraining from a meal $2 \mathrm{~h}$ prior to testing, is difficult to ensure in clinical practice. In our experience, patients attending the respiratory laboratory are frequently non-compliant with other instructions, such as withholding short-acting bronchodilators or cigarettes. In addition to this, respiratory patients may be elderly and often demonstrate cognitive dysfunction due to long-term hypoxia., ${ }^{8,9}$ These patients may misunderstand the instruction and fast inappropriately prior to testing. Fasting unnecessarily increases the risk of adverse events, particularly in 
patients who may be acutely unwell and have other comorbidities. The purpose of this study is to determine whether abstaining from a meal prior to lung function testing is necessary in clinical practice.

\section{METHODS}

\section{Subjects}

Three groups were recruited for this study: healthy subjects, patients with interstitial lung disease (ILD) and patients with COPD. The healthy subjects were non-smoking hospital staff with no history of lung disease. This group included five out of 12 subjects, who were laboratory staff and who were not naive to lung function testing. ILD and COPD patients were recruited from respiratory outpatient clinics at Royal Perth Hospital over a 1-year period. Patients who had attended the laboratory as an outpatient for full lung function tests, who fulfilled entry criteria and who lived locally, were approached to participate in the study via telephone call by the primary investigator. No patients were naive to lung function testing.

The ILD cohort comprised seven patients with diffuse interstitial fibrosis and three with focal fibrosis. The COPD cohort comprised 10 patients, all of whom had an $\mathrm{FEV}_{1} / \mathrm{FVC}$ ratio less than the lower limit of predicted, ${ }^{10}$ thus fulfilling the ATS/ERS classification of an obstructive ventilatory defect. ${ }^{11}$ All ILD and COPD patients had been diagnosed by a respiratory physician and were clinically stable. Patients with severe COPD $\left(\mathrm{FEV}_{1}<1 \mathrm{~L}\right)$ were not recruited for the study on ethical grounds. Exclusion criteria were: pregnancy, diabetes, mixed obstructive and restrictive respiratory disease, inability to perform lung function testing, inability to give consent or acute illness. This study was approved by the Royal Perth Hospital Ethics Committee and the Charles Sturt University Human Research Ethics Committee.

\section{Study protocol}

All subjects attended the respiratory laboratory on two separate days, no more than 1 week apart. On both study days, subjects fasted from midnight and performed a set of lung function tests at $8 \mathrm{AM}$. On the first visit, the subjects were randomized to the meal or control arm of the study. Subjects on the meal arm of the study were taken to a nearby eatery where they consumed a large meal. Subjects were encouraged to consume a cooked breakfast and to eat as much food as they could, without feeling uncomfortable. Tea or coffee was to be included with their meal. Following the breakfast meal, they returned to the respiratory laboratory and repeated their lung function tests at $9.30 \mathrm{AM}$ and $11.30 \mathrm{AM}$. Subjects on the control arm of the study continued fasting and repeated their lung function tests at $9.30 \mathrm{AM}$ and $11.30 \mathrm{AM}$.

All subjects completed a food diary to determine their usual breakfast intake. This enabled calculation of a kilojoule target for their large meal on the study day. The target for the large meal was $>125 \%$ of the kilojoules in the subject's usual breakfast.

\section{Lung function testing}

Each set of lung function testing included spirometry (Spiroflow, PK Morgan, Kent, UK), measurement of lung volumes and single breath diffusion capacity (Autolink, PK Morgan, Kent, UK). Lung volumes were performed by plethysmography (PK Morgan, Kent, UK) in the healthy group and the helium dilution method (Transfer Test, PK Morgan, Kent, UK) in the patient group due to plethysmograph failure.

The ATS/ERS guidelines ${ }^{12-14}$ for acceptability and repeatability were adhered to. The requirement for $\mathrm{DL}_{\mathrm{CO}}$ repeatability was set to the criterion of two tests within $10 \%$, rather than $3 \mathrm{~mL} / \mathrm{min} / \mathrm{mm} \mathrm{Hg}$. In both of our patient groups, $10 \%$ of their $\mathrm{DL}_{\mathrm{CO}}$ equates to 1-2 $\mathrm{mL} / \mathrm{min} / \mathrm{mm} \mathrm{Hg}$. DL $\mathrm{CO}_{\mathrm{CO}}$ measurements were not corrected for $\mathrm{Hb}$ or carboxyhaemoglobin. The scientist performing the testing was not blinded to the study arms, for practical reasons.

\section{Statistical analysis}

Statistical analyses were performed using a linear mixed mode $l^{15}$ using meal as a fixed effect and time as a random effect. The data analysed comprised $\mathrm{FEV}_{1}$,

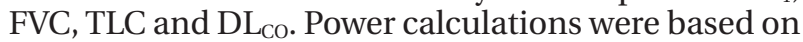
the detection of a $200 \mathrm{~mL}$ change in $\mathrm{FEV}_{1}$, using matched data, where each subject was their own control. Power calculations indicated that 10 subjects would be required in each group.

\section{RESULTS}

Sixty-three eligible subjects were approached to participate in the study. Thirty-two subjects completed the study, 10 patients with ILD, 10 patients with COPD and 12 healthy subjects. Subject demographics and baseline lung function are provided in Table 1. The demographics of the ILD and COPD groups were similar; however, the healthy subjects tended to be younger and taller. The primary reason for nonparticipation in the study was that patients felt it would be 'too much'.

All subjects consumed $>125 \%$ of the kilojoules in their usual breakfast during the meal arm of the study and were therefore considered to have eaten a large meal. The total kilojoule content of the meals is also shown in Table 1.

Figure 1 shows the mean postprandial values for $\mathrm{FEV}_{1}, \mathrm{FVC}$, TLC and $\mathrm{DL}_{\mathrm{CO}}$, at $9.30 \mathrm{AM}$ and $11.30 \mathrm{AM}$, in all groups. The ordinate axis in the graphs represent the repeatability criteria of the measurement based on the ATS/ERS criteria. ${ }^{12-14}$ For both patient groups and healthy subjects, the $\mathrm{FEV}_{1}$ was reproducible over the course of the morning (Fig. 1a). The linear mixed model analysis for $\mathrm{FEV}_{1}$ showed no statistical significant effect of a meal, with $P>0.8$ for all groups. Figure $1 \mathrm{~b}$ displays the data for FVC, which, similarly 
Table 1 Demographic characteristics, baseline lung function and large meal of the subjects who completed the study

\begin{tabular}{lccc}
\hline & Healthy & COPD & ILD \\
\hline Number of subjects & 12 & 10 & 10 \\
Gender, M/F & $6 / 6$ & $6 / 4$ & $5 / 5$ \\
Age, years & $40 \pm 13$ & $65 \pm 9$ & $167 \pm 10$ \\
Height, cm & $174 \pm 11$ & $165 \pm 8$ & $84 \pm 17$ \\
Weight, kg & $74 \pm 16$ & $75 \pm 16$ & $30 \pm 5$ \\
BMI, kg/m $^{2}$ & $24 \pm 4$ & $27 \pm 6$ & $86 \pm 19$ \\
FEV $_{1} \%$ predicted $^{10}$ & $97 \pm 18$ & $73 \pm 21$ & $84 \pm 20$ \\
FVC, $\%$ predicted $^{10}$ & $99 \pm 15$ & $99 \pm 20$ & $73 \pm 12$ \\
TLC, $\%$ predicted $^{16}$ & $109 \pm 12$ & $112 \pm 9$ & $57 \pm 9$ \\
DL $_{\text {co, \% predicted }}$ & $90 \pm 11$ & $78 \pm 19$ & $2338(2245-2390)$ \\
Size of large meal, kJ $_{\% \text { of usual breakfast }}$ & $4135(1495-9335)$ & $2622(795-3920)$ & $213(133-371)$ \\
\hline
\end{tabular}

Total kilojoule content for the large meal consumed on the study day is also shown. Data are presented as number or mean \pm SD.

ILD, interstitial lung disease.

Figure 1 Mean postprandial changes in lung function test results over the course of a morning, in patients with COPD $(n=10)$, interstitial lung disease (ILD) $(n=10)$ and in healthy subjects $(n=12)$. Lung function parameters included measurement of forced flows: (a) $\mathrm{FEV}_{1}$ and (b) FVC, as well as static lung volumes (c) TLC and diffusion capacity (d) $D L_{c o}$. There was no significant effect of meal on lung function in any group, with all $P>0.4$. (口) COPD group; ( $\square$ ILD group; ( Healthy group.
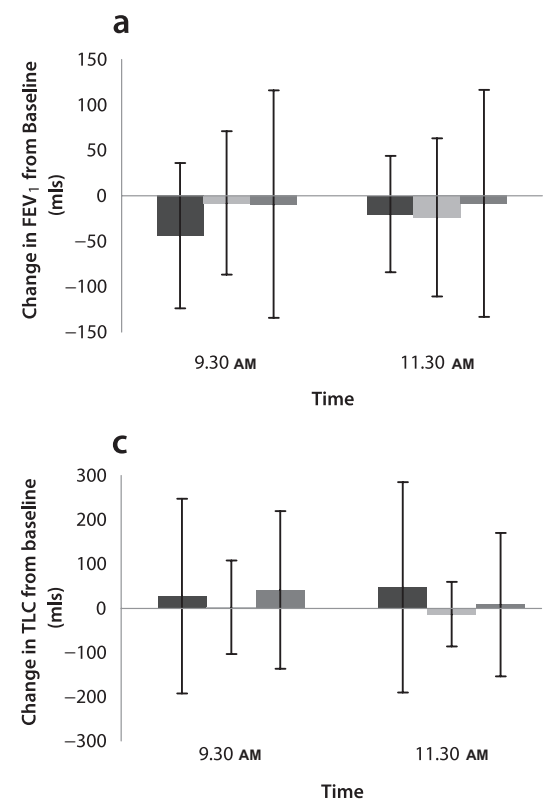

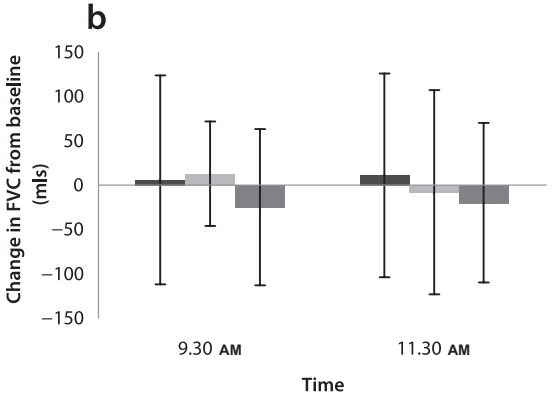

d

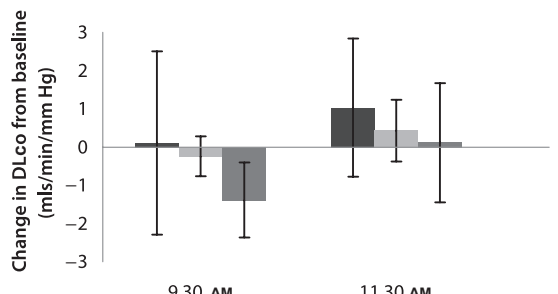

to $\mathrm{FEV}_{1}$, remained unchanged (for all, $P>0.9$ ). TLC, shown in Figure 1c, also showed no effect of a meal $(P>0.8$ in all groups). Additionally, there was no evidence of effect on $\mathrm{DL}_{\mathrm{CO}}$ (data shown in Fig. 1d) with $P>0.4$ in all groups.

\section{DISCUSSION}

The results from the current study do not support the suggestion that a large meal prior to lung function testing affects results. Other studies investigating the effect of meals have focused on spirometry, measurements of airway inflammation and basal metabolic rates. Akrabawi et al. ${ }^{3}$ investigated the effect of meals in COPD patients. In that study, 36 patients consumed a 12 ounce meal, of either high or moderately high fat formula. Spirometry, $\mathrm{V}_{\mathrm{O}_{2}}$ and $\mathrm{V}_{\mathrm{CO}_{2}}$ were measured at 0, 30, 90 and $150 \mathrm{~min}$ post meal. No meal effect was seen in spirometry; however, changes in $\mathrm{V}_{\mathrm{O}_{2}}$ and $\mathrm{V}_{\mathrm{CO}_{2}}$ did occur. Rosenkranz ${ }^{5}$ also reported no effect of a meal on spirometry in healthy subjects.

Another study $^{17}$ that examined the effect of Ramadan fasting on lung function showed no difference in spirometry between pre-Ramadan and during Ramadan; however, details of the meal times in the pre-Ramadan period compared with test times were not specified. In contrast to these reports, a study by Mroueh and Spock ${ }^{4}$ found four out of 12 stable cystic fibrosis patients had a decrease in FVC of more than $5 \%$, which occurred $10 \mathrm{~min}$ post meal. This was considered to be statistically significant, although would 
not be considered clinically significant. ${ }^{11,18}$ The data in the current study showed no postprandial effect on $\mathrm{FEV}_{1}$ or FVC in healthy subjects, COPD or ILD patient groups.

Lung volume measurements in this study were performed by plethysmography in healthy subjects and the helium dilution method in the respiratory patients. Unlike plethysmography, helium dilution will only measure the ventilated spaces in the lungs and will exclude both non-ventilating bullae and extrapulmonary thoracic gas. ${ }^{19}$ This may account for the baseline \% predicted TLC for the COPD group being similar to the baseline \% predicted TLC for the healthy group. TLC measurement, by both techniques, is dependent on the subject's ability to inspire and expire maximally. Thus, TLC may be limited by abdominal distension, causing discomfort and restricting the ability of the lung to expand. Ventilatory pattern changes, such as an increase in respiratory rate with a fall in tidal volume, may affect lung volume subdivisions, such as FRC, but would be compensated by changes in inspiratory capacity, so that no change is seen in TLC. In this study, there were no significant changes in TLC after subjects had consumed a large meal either immediately, or $2 \mathrm{~h}$ prior to testing.

Mechanisms for postprandial changes in $\mathrm{DL}_{\mathrm{CO}}$ have not been investigated, but it is widely assumed ${ }^{1,2,7,20}$ that meals prior to testing will decrease $\mathrm{DL}_{\mathrm{CO}}$. The rationale behind this is that the redistribution of blood flow from the pulmonary capillaries to the splancnic regions, which occurs for digestive purposes after a meal, will reduce pulmonary perfusion. In addition to this, any mechanisms that affect FVC or TLC would also affect DL $\mathrm{DO}_{\mathrm{CO}}$. Besides pulmonary perfusion, the main factors that influence $\mathrm{DL}_{\mathrm{CO}}$ are the conductivity of the alveolar-capillary membrane and the reaction rate of $\mathrm{Hb}$ with carbon monoxide. ${ }^{14}$ Thus, the reproducibility of $\mathrm{DL}_{\mathrm{CO}}$ between sessions can vary depending on many different factors, including recent exercise, smoking, Hb level and time of day. ${ }^{21-25}$ Technical factors, including equipment used, breathhold time and depth of inspiration can also influence results. For these reasons, $\mathrm{DL}_{\mathrm{CO}}$ has a much higher variability than other lung function tests. The ATS/ ERS guidelines for measurement of diffusing capacity $^{14}$ allow a repeatability of within three units, or $10 \%$, whichever is greater. The acceptable results from a testing session are then averaged for the reported result. The change in $\mathrm{DL}_{\mathrm{CO}}$ required for clinical significance is uncertain. Robson and Innes ${ }^{26}$ studied the natural variability of $\mathrm{DL}_{\mathrm{CO}}$ over 1 week. They reported coefficients of repeatability for $\mathrm{DL}_{\mathrm{CO}}$ of $1.84 \mathrm{mmol} /$ $\mathrm{min} / \mathrm{kPa}(5.5 \mathrm{~mL} / \mathrm{min} / \mathrm{mm} \mathrm{Hg})$ in healthy subjects and $1.30 \mathrm{mmol} / \mathrm{min} / \mathrm{kPa}(3.9 \mathrm{~mL} / \mathrm{min} / \mathrm{mm} \mathrm{Hg})$ in patients with emphysema. In the current study, the between session repeatability was found to be within these limits, and no statistically significant effect of meals on $\mathrm{DL}_{\mathrm{CO}}$ was seen, providing further evidence that avoiding a large meal prior to lung function testing is unnecessary.

In the current study, tea or coffee was included in all of the meals. Caffeine is a known stimulant of ventilation $^{27}$ and has a bronchodilator effect similar to theophylline. ${ }^{28}$ Caffeine has been shown to increase $\mathrm{FEV}_{1}$ in asthmatics ${ }^{28,29}$ and is effective at preventing exercise-induced bronchoconstriction at doses of $7 \mathrm{mg} / \mathrm{kg} \cdot{ }^{30}$ Bronchodilation of airways has been shown to increase $\mathrm{DL}_{\mathrm{CO}}$ by reducing expiration time, and improvements in volume and distribution of inhaled gas. ${ }^{31-33}$ In addition to this, similar to the proposed effect of a large meal, it is possible that the vasodilator effects of caffeine may decrease $\mathrm{DL}_{\mathrm{CO}}$ by the redistribution of blood from the pulmonary capillaries to the muscles and brain. However, given that the doses of caffeine in previous studies (5-7 $\mathrm{mg} / \mathrm{kg}$ ) are higher than in the present study, we believe it unlikely that including tea or coffee with a meal affected the results. Furthermore, we have previously evaluated the effects of drinking coffee on $\mathrm{FEV}_{1}$ and $\mathrm{DL}_{\mathrm{CO}}$ in a separate study, ${ }^{34}$ using a similar protocol, which found no effect.

This study has several limitations. First, we were unable to measure and correct for $\mathrm{Hb}$. We did not consider measurement of carboxyhaemoglobin levels to be necessary, as none of the study subjects were current smokers. Another limitation to this study is that the scientist performing the lung function testing was not blinded to the study arm of the subjects. Additionally, the limited sample size may not have detected small changes in lung function, which may be significant for research purposes, but these changes are unlikely to be clinically significant.

In conclusion, this study directly assessed the need to withhold large meals prior to lung function testing, and is the first study to examine postprandial effects on the measurement of lung volumes and gas diffusion. This study did not demonstrate any statistically significant postprandial changes in lung function. In the context of a clinical respiratory laboratory the present findings do not support the ATS/ERS recommendation that patients withhold meals prior to performing their lung function tests.

\section{ACKNOWLEDGEMENTS}

This study was supported by Royal Perth Hospital.

\section{REFERENCES}

1 Miller MR, Crapo R, Hankinson J et al. General considerations for lung function testing. Eur. Respir. J. 2005; 26: 153-62.

2 Mottram C, Blonshine S, Brown R et al. AARC clinical practice guideline, single-breath carbon monoxide diffusing capacity. Respir. Care 1999; 44: 539-46.

3 Akrabawi SS, Mobarhan S, Stoltz RR et al. Gastric emptying, pulmonary function, gas exchange, and respiratory quotient after feeding a moderate verses high fat enteral formula meal in chronic obstructive pulmonary disease patients. Nutrition 1996; 12: 260-5.

4 Mroueh S, Spock A. Effects of meals on respiratory functions in patients with cystic fibrosis. Pediatr. Asthma Allergy Immunol. 1992; 6: 87-91.

5 Rosenkranz SK, Townsend DK, Steffens SE et al. Effects of a highfat meal on pulmonary function in healthy subjects. Med. Sci. Sports Exerc. 2007; 39: S342. 
6 Cotes JE. Lung Function: Assessment and Application in Medicine. Blackwell Scientific Publications, Oxford, 1975.

7 American Thoracic Society (ATS). Single-breath carbon monoxide diffusing capacity (transfer factor). Recommendations for a standard technique-1995 update. Am. J. Respir. Crit. Care Med. 1995; 152: 2185-98.

8 Incalzi RA, Gemma A, Marra C et al. Chronic obstructive pulmonary disease. An original model of cognitive decline. Am. Rev. Respir. Dis. 1993; 148: 418-24.

9 Prigatano GP, Parsons O, Wright E et al. Neuropsychological test performance in mildly hypoxemic patients with chronic obstructive pulmonary disease. J. Consult. Clin. Psychol. 1983; 51: 108-16.

10 Knudson RJ, Lebowitz MD, Holberg CJ et al. Changes in the normal maximal expiratory flow-volume curve with growth and aging. Am. Rev. Respir. Dis. 1983; 127: 725-34.

11 Pellegrino R, Viegi G, Brusasco V et al. Interpretive strategies for lung function tests. Eur. Respir. J. 2005; 26: 948-68.

12 Miller MR, Hankinson J, Brusasco V et al. Standardisation of spirometry. Eur. Respir. J. 2005; 26: 319-38.

13 Wanger J, Clausen JL, Coates A et al. Standardisation of the measurement of lung volumes. Eur. Respir. J. 2005; 26: 511-22.

14 MacIntyre N, Crapo RO, Viegi G et al. Standardisation of the single-breath determination of carbon monoxide uptake in the lung. Eur. Respir. J. 2005; 26: 720-35.

15 Molenberghs G, Laenen A, Vangeneugden T. Estimating reliability and generalizability from hierarchical biomedical data. $J$. Biopharm. Stat. 2007; 17: 595-672.

16 Crapo RO, Morris AH, Clayton PD et al. Lung volumes in healthy nonsmoking adults. Bull. Eur. Physiopathol. Respir. 1982; 18: 41925.

17 Siddiqui QA, Sabir S, Subhan MF. The effect of Ramadan fasting on spirometry in healthy subjects. Respirology 2005; 10: 525-8.

18 NAC. Asthma Management Handbook. National Asthma Council Australia, Melbourne, 2006.

19 Quanjer PH, Tammeling GJ, Cotes JE et al. Lung volumes and forced ventilatory flows. Report Working Party, Standardization of Lung Function Tests, European Community for Steel and Coal and European Respiratory Society. Eur. Respir. J. 1993; 6 (Suppl. 16): S5-40.

20 Cotes JE, Chinn DJ, Quanjer PH et al. Standardization of the measurement of transfer factor (diffusing capacity). Report Working Party Standardization of Lung Function Tests, European
Community for Steel and Coal. Official Statement of the European Respiratory Society. Eur. Respir. J. 1993; 6 (Suppl. 16): 41-52.

21 Hsia CC. Recruitment of lung diffusing capacity: update of concept and application. Chest 2002; 122: 1774-83.

22 Viegi G, Baldi S, Begliomini E et al. Single breath diffusing capacity for carbon monoxide: effects of adjustment for inspired volume dead space, carbon dioxide, hemoglobin and carboxyhemoglobin. Respiration 1998; 65: 56-62.

23 Cotes JE, Dabbs JM, Elwood PC et al. Iron-deficiency anaemia: its effect on transfer factor for the lung (diffusing capacity) and ventilation and cardiac frequency during sub-maximal exercise. Clin. Sci. 1972; 42: 325-35.

24 Cinkotai FF, Thomson ML. Diurnal variation in pulmonary diffusing capacity for carbon monoxide. J. Appl. Physiol. 1966; 21: 539-42.

25 Frey TM, Crapo RO, Jensen RL et al. Diurnal variation of the diffusing capacity of the lung: is it real? Am. Rev. Respir. Dis. 1987; 136: $1381-4$

26 Robson AG, Innes JA. Short term variability of single breath carbon monoxide transfer factor. Thorax 2001; 56: 358-61.

27 Funk GD. Losing sleep over the caffeination of prematurity. J. Physiol. 2009; 587: 5299-300.

28 Becker AB, Simons KJ, Gillespie CA et al. The bronchodilator effects and pharmacokinetics of caffeine in asthma. N. Engl. J. Med. 1984; 310: 743-6.

29 Bukowskyj M, Nakatsu K. The bronchodilator effect of caffeine in adult asthmatics. Am. Rev. Respir. Dis. 1987; 135: 173-5.

30 Kivity S, Aharon YB, Man A et al. The effect of caffeine on exercise-induced bronchoconstriction. Chest 1990; 97: 1083-5.

31 Akesson U, Dahlstrom JA, Wollmer P. Changes in transfer factor of the lung in response to bronchodilatation. Clin. Physiol. 2000; 20: 14-18.

32 Chinn DJ, Askew J, Rowley L et al. Measurement technique influences the response of transfer factor (TLCO) to salbutamol in patients with airflow limitation. Eur. Respir. J. 1988; 1: 15-21.

33 Ogilvie CM, Forster RE, Blakemore WS et al. A standardized breath holding technique for the clinical measurement of the diffusing capacity of the lung for carbon monoxide. J. Clin. Invest. 1957; 36: 1-17.

34 McKeon E, Nathan C, McArdle N et al. Coffee consumption does not affect lung function in healthy subjects. Respirology 2006; 11 (Suppl. 2): A5. 